\title{
BMJ Open Willingness of patients with sarcoma to participate in cancer surveillance research: a cross-sectional patient survey
}

\author{
Patricia Schneider (D) , ${ }^{1}$ Victoria Giglio (D) , ${ }^{1}$ Dana Ghanem, ${ }^{1}$ David Wilson, ${ }^{1}$ \\ Robert Turcotte, ${ }^{2}$ Marc Isler, ${ }^{3}$ Sophie Mottard, ${ }^{3}$ Benjamin Miller, ${ }^{4}$ James Hayden, ${ }^{5}$ \\ Yee-Cheen Doung, ${ }^{5}$ Kenneth Gundle (D) , ${ }^{5} \mathrm{R}$ Lor Randall, ${ }^{6}$ Kevin Jones, ${ }^{7}$ \\ Roberto Vélez, ${ }^{8}$ Michelle Ghert ${ }^{1,9}$
}

To cite: Schneider $P$, Giglio V, Ghanem D, et al. Willingness of patients with sarcoma to participate in cancer surveillance research: a cross-sectional patient survey. BMJ Open 2021;11:e042742. doi:10.1136/ bmjopen-2020-042742

- Prepublication history and supplemental material for this paper is available online. To view these files, please visit the journal online (http://dx.doi. org/10.1136/bmjopen-2020042742).

Received 13 July 2020 Revised 20 January 2021 Accepted 08 February 2021

Check for updates

(C) Author(s) (or their employer(s)) 2021. Re-use permitted under CC BY-NC. No commercial re-use. See rights and permissions. Published by BMJ.

For numbered affiliations see end of article.

Correspondence to

Dr Michelle Ghert;

ghertm@mcmaster.ca

\section{ABSTRACT}

Objectives To determine the proportion of patients with extremity sarcoma who would be willing to participate in a clinical trial in which they would be randomised to one of four different postoperative sarcoma surveillance regimens. Additionally, we assessed patients' perspectives on the burden of cancer care, factors that influence comfort with randomisation and the importance of cancer research.

Design Prospective, cross-sectional patient survey. Setting Outpatient sarcoma clinics in Canada, the USA and Spain between May 2017 and April 2020. Survey data were entered into a study-specific database.

Participants Patients with extremity sarcoma who had completed definitive treatment from seven clinics across Canada, the USA and Spain.

Main outcome measures The proportion of patients with extremity sarcoma who would be willing to participate in a randomised controlled trial (RCT) that evaluates varying postoperative cancer surveillance regimens.

Results One hundred thirty complete surveys were obtained. Respondents reported a wide range of burdens related to clinical care and surveillance. The majority of patients $(85.5 \%)$ responded that they would agree to participate in a cancer surveillance RCT if eligible. The most common reason to participate was that they wanted to help future patients. Those that would decline to participate most commonly reported that participating in research would be too much of a burden for them at a time when they are already feeling overwhelmed. However, most patients agreed that cancer research will help doctors better understand and treat cancer.

Conclusions These results demonstrate that most participants would be willing to participate in an RCT that evaluates varying postoperative cancer surveillance regimens. Participants' motivation for trial participation included altruistic reasons to help future patients and deterrents to trial participation included the overwhelming burden of a cancer diagnosis. These results will help inform the development of patient-centred RCT protocols in sarcoma surveillance research.

Level of evidence $V$.

\section{INTRODUCTION}

Sarcomas are a rare and heterogenous group of cancers with distinct biology that represent
Strengths and limitations of this study

The primary objective of this study was to investigate the proportion of patients with extremity sarcoma who would be willing to participate in a clinical trial in which they would be randomised to one of four different postoperative cancer surveillance regimens.

- The results of this study have been used to directly inform the definitive phase of the Surveillance AFter Extremity Tumor SurgerY (SAFETY) trial.

- Patient engagement in the preliminary trial development is expected to improve the trial's relevance, increase transparency and, ultimately, accelerate the adoption of findings into practice.

- Patients who agreed to participate in the survey study may be more likely to participate in research in general, thus possibly introducing selection bias.

- This may have resulted in an overestimation of the acceptance rate of the SAFETY study and interest in clinical research; however, our response rate of $92 \%$ may have somewhat mitigated these concerns.

$<1 \%$ of all malignancies. ${ }^{1-6}$ Following treatment for a sarcoma, patients remain at risk for the development of local and systemic disease recurrence, which necessitates careful postoperative surveillance. Almost $50 \%$ of all patients with sarcoma will develop a local or distant recurrence; however, the risk of recurrence is greatest in the first few years, with $68 \%$ occurring by 2 years and $90 \%$ by 5 years. ${ }^{7-9}$ Metastasis to the lung is the most frequent single location of disease recurrence in patients with sarcoma, occurring in approximately one-half of all patients. ${ }^{9-12}$ Earlier detection of less advanced and resectable disease relapse may prolong patient survival; however, once advanced metastases are detected, the median length of survival is 12-15 months. ${ }^{9}$

As such, routine follow-up following the completion of sarcoma treatment is standard 
practice, and generally entails regular visits to sarcoma outpatient clinics in the first 5-10 years after surgery. These visits typically include a clinical history, a physical examination and imaging of the lungs. Regular, intensive surveillance is more likely to identify recurrent disease earlier than would less intensive surveillance. This may provide reassurance to patients and clinicians as if the interval screening is negative, the patient is considered at that time to be disease-free.

However, the adverse effects of intensive surveillance practices on patients are also noteworthy. Intensive surveillance can threaten the financial security of patients, due in part to the direct costs, including travel, accommodation, personal care and homemaking, and indirect costs, including lost wages for patients and their caregivers, incurred as a result of follow-up appointments. ${ }^{13}$ As a result, patients' health and quality of life can be dramatically impacted should they decide to forego further treatment or alter their lifestyles in order to alleviate financial difficulties. ${ }^{13-15}$ Furthermore, intensive surveillance investigations can also induce anxiety, and earlier knowledge of disease recurrence may adversely impact patients' psychosocial well-being for those whose mortality risk cannot be significantly reduced by further medical interventions. ${ }^{16}$ In fact, the first recommendation put forward by Choosing Wisely Canada for oncology is not to 'order tests to detect recurrent cancer in asymptomatic patients if there is not a realistic expectation that early detection of recurrence can improve survival or quality of life' ${ }^{17}$

A randomised controlled trial (RCT) would be the ideal approach to determine the optimal postoperative surveillance strategy that balances potential gains in survival, costs and quality of life. Given the rarity of sarcoma, possible patient anxiety related to both lessintensive and more-intensive sarcoma surveillance and the fact that clinical trial recruitment is often slower than anticipated, such an RCT will require extensive international collaboration and patient willingness to be randomly allocated to varying surveillance regimens. Patients' perceptions of surveillance and of participation in a surveillance RCT are required in order to develop a study protocol that is patient-centred, compelling and feasible, and is capable of answering this high priority clinical question in a reasonable timeframe. ${ }^{18} 19$ In this study, we conducted a patient survey to investigate the proportion of patients with extremity sarcoma that would be willing to participate in a clinical trial in which they would be randomised to one of four different postoperative sarcoma surveillance regimens. We also assessed the burden of cancer care on patients, the factors that influence patient comfort with being randomised to different surveillance protocols and we explored patients' views on the importance of cancer research.

\section{METHODS}

We conducted a cross-sectional multicentre survey between May 2017 and April 2020 at seven sarcoma outpatient clinics in Canada (three sites), the USA (three sites) and Spain (one site).

\section{Participants}

Clinical sites

The clinical sites within our international orthopaedic oncology research network were carefully screened for the following criteria: (1) sufficiently high sarcoma volume defined as $\geq 20$ participants per year; (2) adequate research personnel and infrastructure to manage the study and (3) an interest in participating in the Surveillance AFter Extremity Tumor surgerY (SAFETY) trial. The clinical sites that met the eligibility criteria were invited to participate in this cross-sectional study.

\section{Patients}

In order to be eligible for participation, patients must have: (1) been at least 18 years of age; (2) been able to read, understand and write in English, French or Spanish; (3) have recently completed treatment of an extremity sarcoma and (4) provided consent to participate.

\section{Questionnaire objectives}

Given that patients' willingness to participate in cancer surveillance research is the ultimate determinant of overall study feasibility, the primary objective of this questionnaire was to determine whether patients with extremity sarcoma would be willing to participate in the SAFETY trial. ${ }^{20}$ The SAFETY trial, initiated in early 2020 , is a $2 \times 2$ factorial design RCT in which patients with sarcoma are randomised to one of four different surveillance regiments. The primary objective of the SAFETY trial is to determine the effect of surveillance intensity on long-term survival in the soft-tissue sarcoma population. The current cross-sectional survey served as background work for the trial's development.

The secondary objectives of this cross-sectional patient survey included: (1) assessment of the burden of cancer care on patients; (2) assessment of factors that influence patient comfort with being randomised to different surveillance protocols and (3) the exploration of patients' views on the importance of cancer research.

\section{Questionnaire development \\ Item generation}

We developed a unique patient questionnaire for the purpose of this study. The development of this questionnaire was informed by a review of the current literature on patient surveillance and in consultation with experts in orthopaedic oncology, research methodology and patient recruitment. We utilised a 'sampling-to-redundancy' approach in which we solicited feedback from new orthopaedic oncologists and research methodologists until no new items for the questionnaire emerged.

\section{Pretesting and validity assessments}

The questionnaire was reviewed by nine additional experts, who were either orthopaedic oncologists or health research methodologists. These experts 
evaluated whether the questionnaire as a whole appeared to adequately address the question of whether patients with extremity sarcoma would participate in cancer surveillance research (face validity) and whether the individual questions adequately addressed the objectives of the current study (content validity). These nine experts also assessed the questionnaire's comprehensiveness and flow, as well as identified any redundant, irrelevant or poorly worded questions.

\section{Survey description}

The final survey comprised 58 questions using Likert scales, multiple choice and brief open-ended questions. The following sections were included: (a) demographics, including medical history and income; (b) cancer history, including the number of treatment visits thus far required; (c) perceptions of cancer research; (d) financial burden of cancer care; (e) logistical burden of cancer care and (f) the SAFETY trial, including perceptions of cancer surveillance, the trial design and willingness to participate in such a trial and reasons for accepting or declining to participate. The survey is provided in online supplemental appendix 1 .

All questions were straightforward and used clear and layman terminology to enhance the validity of the results. The survey length was kept to a minimum in an effort to maximise the response rate and to limit barriers that could have affected its proper completion.

\section{Sample size}

Convenience sampling of consecutive patients was used at the seven participating sites. One hundred thirty patients completed the patient survey, which represents a robust sample in the study of rare diseases. ${ }^{21}$

\section{Survey administration and data collection}

Initially, we approached all patients with extremity sarcoma in person that had consented for sarcoma surgery. However, after consulting with the SAFETY trial's Steering Committee members on the study's protocol in May 2018, we determined that patients would be approached, consented and randomised into the SAFETY trial after definitive treatment for their extremity sarcoma, as it was deemed a less stressful time for patients to make an informed decision, as well as a time point closer to the initiation of surveillance. After this decision was made, we began approaching all recent postoperative patients with extremity sarcoma for participation in this survey study, either at a postoperative clinical appointment or via telephone. After obtaining informed consent, the site study coordinator provided each participant with a paper copy of the questionnaire to complete in a private location. Participants were allowed to leave a question blank if they found it uncomfortable to answer. On completion, the participant returned the questionnaire to the site study coordinator who verified that all questions had been answered. Completed questionnaires were then entered into a study-specific database using the REDCap electronic data capture software system.

\section{Statistical analysis}

Descriptive analyses, including frequency counts and percentages, were calculated for all collected data. Continuous data were presented as means and SD.

\section{Role of the funding source}

The funding source had no role in the design or conduct of the study; the collection, management, analysis or interpretation of the data or the preparation, review or approval of the manuscript. None of the authors has been paid to write this article. The study team had full access to all of the study data and takes responsibility for the integrity of the data and the accuracy of the data.

\section{Patient and public involvement}

Although this study evaluates the patients' perspectives on participating in clinical trials and cancer research, patients were not involved in the design, conduct or reporting or dissemination of this research. However, the results of this study will help inform the development of patient-centred clinical trial protocols in sarcoma surveillance research.

\section{RESULTS}

\section{Characteristics of respondents}

A total of 142 patients were approached to complete the survey and 130 agreed (response rate 92\%). To the best of our knowledge, no patients were missed during the recruitment period. Participant demographic and cancer history data are shown in Table 1 . The mean participant age was 56.4 years (SD 16.9 years) and $60.8 \%$ of participants were male. The majority of patient respondents were white $(82.3 \%)$ and country of residence was reported as Canada in $40.8 \%$, the USA in $52.3 \%$ and Spain in $6.9 \%$ of respondents. Most respondents were married or in a common law relationship $(70.5 \%)$. There was a broad range of educational levels reported with a high school diploma as the most common response $(31.3 \%)$, and a wide range of household incomes were reported. The most common anatomic location for the sarcoma was the lower extremity $(66.7 \%)$, and participants reported receiving multidisciplinary treatment including chemotherapy $(21.9 \%)$ and radiotherapy $(68.4 \%)$. Travel times to the clinic ranged evenly across the spectrum from $<30$ min to $>2$ hours. Most participants reported travelling to medical appointments by personal vehicle $(75 \%)$ by themselves $(46.9 \%)$ or with a spouse $(41.4 \%)$. Seventyfive per cent of patient respondents reported not having previously been involved in a clinical research study.

\section{Burden of cancer care}

Respondent details for burden of cancer care are shown in table 2. The majority of participants reported at least some form of financial burden related to their cancer care and surveillance. These included transportation 


\section{Table 1 Participant demographics}

\section{Characteristic}

Age (years), mean (SD)

Gender, $\mathrm{n}(\%)$

\begin{tabular}{|c|c|}
\hline Male & $79(60.8)$ \\
\hline Female & $51(39.2)$ \\
\hline \multicolumn{2}{|l|}{ Ethnicity, n (\%) } \\
\hline White/Caucasian & $107(82.3)$ \\
\hline Black & $3(2.3)$ \\
\hline Native & $1(0.8)$ \\
\hline Asian & $4(3.1)$ \\
\hline Hispanic & $9(6.9)$ \\
\hline Other (specify) & $5(3.8)$ \\
\hline \multicolumn{2}{|l|}{ Country, n (\%) } \\
\hline Canada & $53(40.8)$ \\
\hline USA & $68(52.3)$ \\
\hline Spain & $9(6.9)$ \\
\hline \multicolumn{2}{|l|}{ Marital status, $\mathrm{n}(\%)$} \\
\hline Single & $20(15.5)$ \\
\hline Separated & $0(0)$ \\
\hline Divorced & $11(8.5)$ \\
\hline Common law & $8(6.2)$ \\
\hline Married & $83(64.3)$ \\
\hline Widowed & $7(5.4)$ \\
\hline \multicolumn{2}{|l|}{ Highest level of education, $\mathrm{n}(\%)$} \\
\hline Did not complete high school & $11(8.6)$ \\
\hline High school diploma & $40(31.3)$ \\
\hline College/Trade diploma & $31(24.2)$ \\
\hline Undergraduate degree & $18(14.1)$ \\
\hline Masters degree & $11(8.6)$ \\
\hline Doctorate degree & $3(2.3)$ \\
\hline Professional degree & $7(5.5)$ \\
\hline \multicolumn{2}{|l|}{ Annual household income, $n(\%)^{*}$} \\
\hline$<\$ 20000$ & $12(9.8)$ \\
\hline$\$ 20000-\$ 39999$ & $25(20.3)$ \\
\hline$\$ 40000-\$ 59999$ & $21(17.1)$ \\
\hline$\$ 60000-\$ 79999$ & $13(10.6)$ \\
\hline$\$ 80000-\$ 99999$ & $15(12.2)$ \\
\hline$\$ 100000+$ & $37(30.1)$ \\
\hline \multicolumn{2}{|l|}{ Cancer type, n (\%) } \\
\hline Chondrosarcoma & $5(3.9)$ \\
\hline Ewing's sarcoma & $1(0.8)$ \\
\hline Fibrosarcoma & $8(6.3)$ \\
\hline Fibrous histiocytoma & $2(1.6)$ \\
\hline Leiomyosarcoma & $4(3.1)$ \\
\hline Liposarcoma & $16(12.6)$ \\
\hline Osteosarcoma & $8(6.3)$ \\
\hline Rhabdomyosarcoma & $4(3.1)$ \\
\hline Synovial sarcoma & $11(8.7)$ \\
\hline
\end{tabular}

Continued
Table 1 Continued

\begin{tabular}{|c|c|}
\hline Characteristic & $\mathrm{N}=130$ \\
\hline Other & $49(38.6)$ \\
\hline \multicolumn{2}{|c|}{ Location of tumour, $\mathrm{n}(\%)$} \\
\hline Upper extremity & $29(22.5)$ \\
\hline Lower extremity & $95(73.6)$ \\
\hline Other & $5(3.9)$ \\
\hline Pelvis & $2(1.6)$ \\
\hline Trunk & $3(2.3)$ \\
\hline \multicolumn{2}{|c|}{ Cancer treatment modalities, $n(\%)$} \\
\hline Chemotherapy & $25(21.9)$ \\
\hline Radiation therapy & $78(68.4)$ \\
\hline Physiotherapy & $4(3.5)$ \\
\hline Other & $46(40.4)$ \\
\hline \multicolumn{2}{|c|}{ Travel time to sarcoma clinic, $\mathrm{n}(\%)$} \\
\hline$<30 \mathrm{~min}$ & $24(18.6)$ \\
\hline $30-59$ min & $38(29.5)$ \\
\hline $60-89 \min$ & $19(14.7)$ \\
\hline $90-119 \min$ & $23(17.8)$ \\
\hline $120 \min +$ & $25(19.4)$ \\
\hline
\end{tabular}

Primary mode of transportation to sarcoma clinic, $\mathrm{n}(\%)$

$\begin{array}{lc}\text { Public transit } & 8(6.5) \\ \text { Personal vehicle } & 93(75.0) \\ \text { Taxi } & 3(2.4) \\ \text { Bicycle } & 0(0) \\ \text { Foot } & 1(0.8) \\ \text { Hospital transportation } & 2(1.6) \\ \text { Relative's/Friend's vehicle } & 13(10.5) \\ \text { Other (specify) } & 4(3.2) \\ \text { Primary caregiver, } n \text { (\%) } & \\ \text { Self } & 60(46.9) \\ \text { Spouse/Partner } & 53(41.4) \\ \text { Parent } & 8(6.3) \\ \text { Sibling } & 1(0.8) \\ \text { Child } & 5(3.9) \\ \text { Grandchild } & 0(0) \\ \text { Friend } & 1(0.8) \\ \text { Other (specify) } & 0(0)\end{array}$

Previous participation in research study, $\mathrm{n}(\%)$

$\begin{array}{lc}\text { No } & 98(75.4) \\ \text { Yes } & 32(24.6) \\ 1 & 22(71.0) \\ 2 & 8(25.8) \\ 3 & 1(3.2) \\ >3 & 0(0)\end{array}$

*Participants reporting household income in Euros $(€)$ were converted to $\$ C$ and placed in the respective group at the time of manuscript preparation. Reported household income values include both $\$ C$ and US $\$$ as currency was not collected from participants when responding to this question. 


\begin{tabular}{|c|c|}
\hline Burden & $n=130$ \\
\hline \multicolumn{2}{|l|}{ Financial burdens } \\
\hline \multicolumn{2}{|c|}{ Transportation and travel expenses, $\mathrm{n}(\%)$} \\
\hline No & $16(12.3)$ \\
\hline Yes & $114(87.7)$ \\
\hline \multicolumn{2}{|c|}{ Accommodation and meal expenses, $\mathrm{n}(\%)$} \\
\hline No & $30(23.4)$ \\
\hline Yes & $98(76.6)$ \\
\hline \multicolumn{2}{|c|}{ Family and living expenses, $\mathrm{n}(\%)$} \\
\hline No & $27(21.1)$ \\
\hline Yes & $101(78.9)$ \\
\hline \multicolumn{2}{|c|}{ Caregiving expenses, n (\%) } \\
\hline No & $56(43.8)$ \\
\hline Yes & $72(56.3)$ \\
\hline \multicolumn{2}{|c|}{ Personal loss of wages, $n$ (\%) } \\
\hline Not applicable & $40(31.0)$ \\
\hline No & $40(31.0)$ \\
\hline Yes & $49(38.0)$ \\
\hline \multicolumn{2}{|c|}{ Caregiver loss of wages, n (\%) } \\
\hline Not applicable & $38(29.9)$ \\
\hline No & $62(48.8)$ \\
\hline Yes & 27 (21.3) \\
\hline
\end{tabular}

Logistical burdens

Coordination of frequent medical appointments, $n(\%)$

$\begin{array}{ll}\text { No } & 69(53.5) \\ \text { Yes } & 60(46.5)\end{array}$

Completion and submission of paperwork, $\mathrm{n}(\%)$

$\begin{array}{ll}\text { Not applicable } & 20(15.4) \\ \text { No } & 76(58.5) \\ \text { Yes } & 34(26.2)\end{array}$

Submission of medical bills, $\mathrm{n}(\%)$

\begin{tabular}{ll} 
Not applicable & $28(21.5)$ \\
No & $61(46.9)$ \\
Yes & $41(31.5)$ \\
Arrangement of time off work, $\mathrm{n}(\%)$ & \\
Not applicable & $53(40.8)$ \\
No & $36(27.7)$ \\
Yes & $41(31.5)$ \\
Arrangement of childcare, $\mathrm{n}(\%)$ & \\
Not applicable & $88(67.7)$ \\
No & $27(20.8)$ \\
Yes & $15(11.5)$ \\
\hline
\end{tabular}

and travel expenses $(87.7 \%)$, accommodation and meal expenses $(76.6 \%)$, family and living expenses $(78.9 \%)$, caregiving expenses $(56.3 \%)$ and personal loss of wages (38\%). Logistical burdens are also very significant for some participants. These included coordination of medical visits $(46.5 \%)$, arrangement of time off work $(31.5 \%)$ and arrangement of childcare when applicable.
Table 3 Reasons for trial participation

\begin{tabular}{|c|c|}
\hline Reason & $\begin{array}{l}N=130 \\
N(\%)\end{array}$ \\
\hline $\begin{array}{l}\text { I believe that the study offers the best treatment } \\
\text { available. }\end{array}$ & $65(61.9)$ \\
\hline I want to contribute to scientific research. & $83(79.0)$ \\
\hline $\begin{array}{l}\text { I believe that the quality of care I receive would } \\
\text { be better as part of this study. }\end{array}$ & $42(40.0)$ \\
\hline I trust the doctor treating me. & $79(75.2)$ \\
\hline $\begin{array}{l}\text { I believe the benefits of participating would } \\
\text { outweigh any negative side effects. }\end{array}$ & $53(50.5)$ \\
\hline $\begin{array}{l}\text { I believe the results from the study could benefit } \\
\text { other patients in the future. }\end{array}$ & $82(78.1)$ \\
\hline $\begin{array}{l}\text { I believe that I would be monitored more closely } \\
\text { as part of this study. }\end{array}$ & $42(40.0)$ \\
\hline $\begin{array}{l}\text { I think my cancer will get worse unless I } \\
\text { participate in this study. }\end{array}$ & $1(1.0)$ \\
\hline $\begin{array}{l}\text { I had a positive experience in a previous } \\
\text { research study. }\end{array}$ & $6(5.7)$ \\
\hline Other (specify). & $0(0)$ \\
\hline
\end{tabular}

\section{The SAFETY trial: reasons to participate and views on cancer research}

A summary of patients' perceptions on cancer research and the SAFETY trial specifically are outlined in tables 3 and 4 . The most common reasons for agreeing to participate in cancer research represented trust in the healthcare team and altruism: 'I want to contribute to scientific research' (79\%), 'I trust the doctor treating me' (75\%), "I believe the results from the study could benefit other patients in the future" $(78.1 \%)$ and 'I believe that the study offers the best treatment available' $(61.9 \%)$. With respect to overall views and perceptions of cancer research, approximately two-thirds of participants (68.7\%) feel that they have a good understanding of clinical research. Notably, only about half $(53.5 \%)$ are generally comfortable with the process of randomisation, in which their treatment or surveillance arm could be determined by chance. However, an overwhelming majority of participants $(128 / 130,98.5 \%)$ strongly agree or agree that cancer research will help doctors better understand and treat cancer. In addition, 93.9\% of respondents strongly agree or agree that the primary reason cancer research is done is to improve the treatment of future patients with cancer. Interestingly, over half of respondents $(68 / 130$, $52.3 \%$ ) strongly agree or agree that they would not benefit directly from participating from cancer research.

A total of 106 of 124 respondents that answered the question 'Would you participate in the SAFETY trial if eligible?' reported that they would agree to participate $(85.5 \%)$. Those that believed they would not agree to participate reported that they would decline for the following reasons: (1) 'I do not believe that I can currently cope with the additional requirements of a research study' (eight, respondents, $44.4 \%)$, (2) "I have concerns about possibly being followed 


\begin{tabular}{|c|c|}
\hline View & $\begin{array}{l}N=130 \\
N(\%)\end{array}$ \\
\hline \multicolumn{2}{|c|}{$\begin{array}{l}\text { I am interested in participating in clinical research related to } \\
\text { my cancer. }\end{array}$} \\
\hline Strongly agree & $63(49.2)$ \\
\hline Agree & $51(39.8)$ \\
\hline Neither agree nor disagree & $11(8.6)$ \\
\hline Disagree & $2(1.6)$ \\
\hline Strongly disagree & $1(0.8)$ \\
\hline \multicolumn{2}{|c|}{ I have a good understanding of clinical research. } \\
\hline Strongly agree & $31(24.2)$ \\
\hline Agree & $57(44.5)$ \\
\hline Neither agree nor disagree & $31(24.2)$ \\
\hline Disagree & $3(2.3)$ \\
\hline Strongly disagree & $6(4.7)$ \\
\hline \multicolumn{2}{|c|}{$\begin{array}{l}\text { Some clinical research determines by chance what } \\
\text { treatment a patient receives (randomisation). I am } \\
\text { comfortable with being randomly assigned (randomised) to } \\
\text { receive a treatment. }\end{array}$} \\
\hline Strongly agree & $24(18.6)$ \\
\hline Agree & $45(34.9)$ \\
\hline Neither agree nor disagree & $35(27.1)$ \\
\hline Disagree & $15(11.6)$ \\
\hline Strongly disagree & $10(7.8)$ \\
\hline
\end{tabular}

Cancer research will help doctors better understand and treat cancer.

Strongly agree $102(78.5)$

Agree $26(20.0)$

Neither agree nor disagree

$2(1.5)$

Disagree $0(0)$

Strongly disagree

$0(0)$

The primary reason cancer research is done is to improve the treatment of future patients with cancer.

Strongly agree

$86(66.2)$

Agree $36(27.7)$

Neither agree nor disagree

$3(2.3)$

Disagree

$3(2.3)$

Strongly disagree

$2(1.5)$

I will not directly benefit from participating in cancer research.

$\begin{array}{lc}\text { Strongly agree } & 26(20.0) \\ \text { Agree } & 42(32.3) \\ \text { Neither agree nor disagree } & 31(23.8) \\ \text { Disagree } & 28(21.5) \\ \text { Strongly disagree } & 3(2.3)\end{array}$

Patients who participate in research studies should be told the results when the study is compete.

Strongly agree 46 (35.4)

Continued
Table 4 Continued

\begin{tabular}{|c|c|}
\hline View & $\begin{array}{l}N=130 \\
N(\%)\end{array}$ \\
\hline Agree & $62(47.7)$ \\
\hline Neither agree nor disagree & $20(15.4)$ \\
\hline Disagree & $1(0.8)$ \\
\hline Strongly disagree & $1(0.8)$ \\
\hline \multicolumn{2}{|c|}{$\begin{array}{l}\text { I would agree to participate in the SAFETY trial if eligible } \\
(n=124) \text {. }\end{array}$} \\
\hline Yes & 106 (85.5) \\
\hline No & $18(14.5)$ \\
\hline
\end{tabular}

SAFETY, Surveillance AFter Extremity Tumor SurgerY.

less intensively in this study" (four respondents, 22.2\%), (3) "I have concerns about additional radiation exposures from CT scans" (four respondents, 22.2\%) and (4) "I believe that the quality of care I receive would be inferior to what I would receive if I did not participate" (three respondents, 16.7\%). Other less common reasons to decline the study included "I do not believe that the study offers the best treatment available", "My family is not keen for me to participate" and travel and religious reasons. One respondent reported a negative experience with a previous trial.

\section{DISCUSSION}

\section{Summary of findings}

This study explored the perceptions of international patients with extremity sarcoma on cancer surveillance. We found that patients endure significant financial and logistical burdens associated with sarcoma care and follow-up. In general, patients are very interested in participating in clinical research, and specifically in cancer surveillance research. The reasons for participating in research include the desire to help future patients and the perception that their care would be improved in the context of a clinical trial. However, some participants expressed a lingering concern with leaving their care and/or surveillance to chance (randomisation) and several indicated that they believe that they would not participate in research due to feeling overwhelmed with their cancer diagnosis and treatment. Overall, the results of this study will help inform the SAFETY trial and guide approaches to eligible patients when obtaining consent.

\section{Strengths and limitations}

This study has several strengths. First, we used a rigorous process for the development of the patient questionnaire and extensive piloting of the survey. This stepwise process created a questionnaire that was acceptable for patients and sufficiently clear and comprehensive to provide a robust dataset. Second, we surveyed patients across Canada, the USA and Spain. Although this required translation of English documents into French and Spanish, it provided a more global picture of patients' perceptions. The SAFETY trial is an international endeavour, and therefore international 
participation in the background survey was critical. Finally, this survey study represents an important step in engaging patients in randomised controlled trial development and inception, thus improving the patient-centred nature of cancer research.

Our study also had some limitations to consider. First, there may have been selection bias in that those who agreed to participate in the survey study are also more likely to participate in research in general. This would overestimate the acceptance rate of the SAFETY study and interest in clinical research. However, our response rate was $92 \%$, somewhat mitigating these concerns. Second, the survey was not a validated survey; however, it allowed us to determine the proportion of participants who would theoretically consent to participating specifically in the SAFETY trial, as well as investigate patients' views on the burden of cancer care and on cancer research in greater detail than would have been possible with standardised questionnaires. Third, the demographics of the respondents were not diverse with respect to race $(82.3 \%$ white) and continent of residence $(93.1 \%$ from North America). The incidence data collected in the Surveillance, Epidemiology and End Results database of the National Cancer Institute demonstrate similar rates of sarcomas between white and black populations. ${ }^{2-25}$ This is also inconsistent with the overall North American demographic data, as black individuals comprise approximately $13 \%$ of the North American population. ${ }^{26}{ }^{27}$ These demographic discrepancies somewhat limit the external validity of the findings with respect to Europe and other international sites. And while it is not uncommon for non-white racial/ ethnic groups to be under-represented in cancer clinical trials, the race demographics of this survey have highlighted an important gap to address in our recruitment strategy for the SAFETY trial. ${ }^{28-30}$ Fourth, while the survey addressed indirect costs of sarcoma surveillance (such as the cost of travel or missed work to attend a clinic visit), it did not address the direct costs of surveillance (such as the cost to patients of different thoracic imaging techniques or additional imaging and clinic visits). However, postoperative sarcoma surveillance is considered standard of care despite being highly varied among orthopaedic oncologists with respect to thoracic imaging and frequency. ${ }^{31-33}$ Therefore, direct costs should not apply to most patients as a wide spectrum of surveillance care regimens are within the range of standard practice and should be covered by the patients' federal, provincial/state or private health insurance. ${ }^{34}$ Nevertheless, these cost data would likely prove valuable when considering trial participation of patients without private health insurance in countries without socialised healthcare such as the USA. Finally, the survey did not evaluate the optimal timing and method to approach patients to participate in the SAFETY trial.

\section{Relevance to previous research}

The exploration of patients' perceptions of sarcoma surveillance in the context of a randomised surveillance trial has not, to our knowledge, previously been reported. However, as far back as 1979, researchers interviewed patients with sarcoma to determine reasons for acceptance of randomisation in treatment-related clinical trials. ${ }^{35}$ The authors of this study concluded that patient acceptance of participation in treatment-related clinical trials was associated with treatment factors such as burden of care and drug toxicities. Within the field of orthopaedic surgery, Creel $e t a l^{36}$ surveyed patients with meniscal tears and determined willingness to participate in a trial in which they would be randomised to operative versus non-operative treatment. The authors found that lack of strong treatment preferences and male gender were significantly associated with willingness to participate in such a trial. Only $46 \%$ of patients reported that they would be definitely willing or probably willing to participate.

A large survey study of 1227 Swiss patients in which four different clinical trial vignettes were described found that all studies were not equally acceptable to patients. A higher willingness to participate was found when a new drug was considered safe, no extra logistical burden of care was required, results were openly available to the public and the project was approved by a research ethics committee. In contrast, use of placebo controls, and random allocation to study arms were associated with a lower likelihood of participation. ${ }^{37}$ Similarly, Halpern et al found that in patients with hypertension, inconvenience, fear of known side effects and the possibility of receiving placebo were the most common concerns for patients in clinical trials. ${ }^{38}$ Similar to the orthopaedic trial outlined above, only $47 \%$ of patients would be willing to participate in a placebo-controlled trial.

\section{Implications}

In this study, we found that a high percentage of patients with sarcoma would be willing to participate in surveillance research. In comparison to other published patient survey studies of treatment-related RCTs, the willingness to participate identified in this study is significantly greater. This has positive implications for sarcoma surveillance research in general, and specifically for the SAFETY trial. However, survey responses do not necessarily align with actual participation. Moreover, the sense of being overwhelmed with the diagnosis of sarcoma and the need for intensive treatment can deter patients from accepting an additional dimension to their care in the form of a trial. Nevertheless, the patient engagement strategy used in this study is likely to increase enrolment in the SAFETY trial and help guide study implementation. ${ }^{39}$

\section{CONCLUSIONS}

The results of this patient survey demonstrate that the majority of participants would be willing to participate in an RCT that evaluates different postoperative sarcoma surveillance regimens. Participants' motivations for trial participation included trust in the healthcare system and altruistic reasons to help future patients. Those that would decline the study for the most part would do so because of the overwhelming burden of a cancer diagnosis. These results will help inform the development of patient-centred clinical trial protocols in cancer surveillance research and specifically the implementation of the SAFETY trial. 


\section{Author affiliations}

${ }^{1}$ Department of Surgery, McMaster University, Hamilton, Ontario, Canada

${ }^{2}$ Division of Orthopaedic Surgery, McGill University Health Centre, Montreal, Québec, Canada

${ }^{3}$ Department of Orthopaedic Oncology, University of Montreal, Hopital MaisonneuveRosemont, Montreal, Québec, Canada

${ }^{4}$ Department of Orthopaedics and Rehabilitation, University of lowa, lowa City, lowa, USA

${ }^{5}$ Department of Orthopaedics \& Rehabilitation, Oregon Health \& Science University, Portland, Oregon, USA

${ }^{6}$ Department of Orthopaedic Surgery, University of California, Davis, California, USA ${ }^{7}$ Department of Orthopaedics, Huntsman Cancer Institute, University of Utah School of Medicine, Salt Lake City, Utah, USA

${ }^{8}$ Orthopaedic Surgery Department, Hospital Universitario Vall d'Hebron, Barcelona, Spain

${ }^{9}$ Juravinski Cancer Centre, Hamilton Health Sciences, Hamilton, Ontario, Canada

Twitter Patricia Schneider @PJTrouble88, Victoria Giglio @VictoriaGiglio7, Kenneth Gundle @GundleMD and Michelle Ghert @michelle_ghert

Acknowledgements The authors would like to thank all research staff involved in this study: Steven Salomon, MSc (McGill University Health Centre), Hugo Saint-Yves, MSc (Hôpital Maisonneuve-Rosemont), Janie Barry, MSc (Hôpital MaisonneuveRosemont), Tammy Smith, BA, MS (University of lowa), Rebecca Wetzel, BS (Oregon Health \& Sciences University), Jacqueline Hart, AS (University of Utah), Alba LopezFernandez, PhD (Hospital Universitario Vall d'Hebron) and any other research staff from participating sites.

Contributors PS and MG designed this study and are the principal authors of this manuscript. VG and DG contributed significantly to data collection and data analysis. DW, RT, MI, SM, BM, JH, Y-CD, KG, RLR, KJ and RV contributed to the conception of the study and acquisition of data. All authors reviewed and approved the manuscript.

Funding The institution of the authors has received, during the study period, funding from the McMaster Surgical Associates (MSA) Innovation Grant.

Competing interests None declared.

Patient consent for publication Not required.

Ethics approval Each author certifies that his or her institution approved or waived approval (McGill University Health Centre Research Ethics Board) for the human protocol for this investigation and that all investigations were conducted according to the ethical principles of research. The Methods Centre received approval from the Hamilton Integrated Research Ethics Board (HiREB) (Protocol No. 2954). Approval from each of the local ethics committees was obtained in writing prior to the local commencement of the study.

Provenance and peer review Not commissioned; externally peer reviewed.

Data availability statement The datasets generated during this study are not publicly available, but are available from the corresponding author on reasonable request.

Supplemental material This content has been supplied by the author(s). It has not been vetted by BMJ Publishing Group Limited (BMJ) and may not have been peer-reviewed. Any opinions or recommendations discussed are solely those of the author(s) and are not endorsed by BMJ. BMJ disclaims all liability and responsibility arising from any reliance placed on the content. Where the content includes any translated material, BMJ does not warrant the accuracy and reliability of the translations (including but not limited to local regulations, clinical guidelines, terminology, drug names and drug dosages), and is not responsible for any error and/or omissions arising from translation and adaptation or otherwise.

Open access This is an open access article distributed in accordance with the Creative Commons Attribution Non Commercial (CC BY-NC 4.0) license, which permits others to distribute, remix, adapt, build upon this work non-commercially, and license their derivative works on different terms, provided the original work is properly cited, appropriate credit is given, any changes made indicated, and the use is non-commercial. See: http://creativecommons.org/licenses/by-nc/4.0/.

\section{ORCID iDs}

Patricia Schneider http://orcid.org/0000-0003-1425-0687

Victoria Giglio http://orcid.org/0000-0002-4399-9710

Kenneth Gundle http://orcid.org/0000-0003-0451-0561
REFERENCES

1 Ottaviani G, Jaffe N. The epidemiology of osteosarcoma. Cancer Treat Res 2009;152:3-13.

2 Brennan MF, Casper ES, Harrison LB, et al. The role of multimodality therapy in soft-tissue sarcoma. Ann Surg 1991;214:328-38. discussion 336-338.

3 Brennan MF. Management of extremity soft-tissue sarcoma. Am J Surg 1989;158:71-8.

4 Rosen G, Murphy ML, Huvos AG, et al. Chemotherapy, en bloc resection, and prosthetic bone replacement in the treatment of osteogenic sarcoma. Cancer 1976;37:1-11.

5 Eilber FR, Eckhardt J, Morton DL. Advances in the treatment of sarcomas of the extremity. current status of limb salvage. Cancer 1984:54:2695-701.

6 Europe PMC. The changing role of amputation for soft tissue sarcoma of the extremity in adults. - Abstract - Europe PMC, 2020. Available: https://europepmc.org/article/med/1440165

7 Whooley BP, Mooney MM, Gibbs JF, et al. Effective follow-up strategies in soft tissue sarcoma. Semin Surg Oncol 1999;17:83-7.

8 Whooley BP, Gibbs JF, Mooney MM, et al. Primary extremity sarcoma: what is the appropriate follow-up? Ann Surg Oncol 2000;7:9-14.

9 Kane JM. Surveillance strategies for patients following surgical resection of soft tissue sarcomas. Curr Opin Oncol 2004;16:328-32.

10 Gadd MA, Casper ES, Woodruff JM, et al. Development and treatment of pulmonary metastases in adult patients with extremity soft tissue sarcoma. Ann Surg 1993;218:705-12.

11 Huth JF, Eilber FR. Patterns of metastatic spread following resection of extremity soft-tissue sarcomas and strategies for treatment. Semin Surg Oncol 1988;4:20-6.

12 Songür N, Dinç M, Ozdilekcan C, et al. Analysis of lung metastases in patients with primary extremity sarcoma. Sarcoma 2003;7:63-7.

13 Longo CJ, Deber R, Fitch M, et al. An examination of cancer patients' monthly 'out-of-pocket' costs in Ontario, Canada. Eur J Cancer Care 2007;16:500-7.

14 Hopkins RB, Goeree R, Longo CJ. Estimating the National wage loss from cancer in Canada. Curr Oncol 2010;17:40-9.

15 Nipp RD, Zullig LL, Samsa G, et al. Identifying cancer patients who alter care or lifestyle due to treatment-related financial distress. Psychooncology 2016;25:719-25.

16 Thompson CA, Charlson ME, Schenkein E, et al. Surveillance CT scans are a source of anxiety and fear of recurrence in long-term Iymphoma survivors. Ann Oncol 2010;21:2262-6.

17 Mitera G, Earle C, Latosinsky S, et al. Choosing wisely Canada cancer list: ten low-value or harmful practices that should be avoided in cancer care. J Oncol Pract 2015;11:e296-303.

18 Fogel DB. Factors associated with clinical trials that fail and opportunities for improving the likelihood of success: a review. Contemp Clin Trials Commun 2018;11:156-64.

19 Schneider PJ, Evaniew N, McKay P, et al. Moving forward through consensus: a modified Delphi approach to determine the top research priorities in orthopaedic oncology. Clin Orthop Relat Res 2017;475:3044-55.

20 SAFETY Investigators. The surveillance after extremity tumor surgery (safety) trial: protocol for a pilot study to determine the feasibility of a multi-centre randomised controlled trial. BMJ Open 2019;9:e029054.

21 Stoller JK. The challenge of rare diseases. Chest 2018;153:1309-14.

22 Burningham Z, Hashibe M, Spector L, et al. The epidemiology of sarcoma. Clin Sarcoma Res 2012;2:14.

23 Zahm SH, Fraumeni J. The epidemiology of soft tissue sarcoma. Wb Saunders Co 1997;24:504-14.

24 Hsieh M-C, Wu X-C, Andrews PA, et al. Racial and ethnic disparities in the incidence and trends of soft tissue sarcoma among adolescents and young adults in the United States, 1995-2008. J Adolesc Young Adult Oncol 2013;2:89-94.

25 National Cancer Institute. Soft tissue including heart cancer recent trends in SEER age-adjusted incidence rates, 2000-2017, 2021. Available: https://seer.cancer.gov/explorer/application.html?site= $51 \&$ data_type $=1 \&$ graph_type $=2 \&$ compareBy $=$ race \&chk_race_3=3\& chk_race_8 $=8 \&$ sex $=1 \&$ age_range $=1 \&$ stage $=101 \&$ hdn_rate_type $=1 \&$ advopt_precision $=1 \&$ advopt_display $=2$

26 Government of Canada SC. Diversity of the black population in Canada: an overview, 2019. Available: https://www150.statcan.gc. ca/n1/pub/89-657-x/89-657-x2019002-eng.htm

27 US Census Bureau. The black population: 2010. the United States census bureau, 2021. Available: https://www.census.gov/library/ publications/2011/dec/c2010br-06.html

28 Murthy VH, Krumholz HM, Gross CP. Participation in cancer clinical trials: race-, sex-, and age-based disparities. JAMA 2004;291:2720-6. 
29 Baquet CR, Commiskey P, Daniel Mullins C, et al. Recruitment and participation in clinical trials: socio-demographic, rural/urban, and health care access predictors. Cancer Detect Prev 2006;30:24-33.

30 Stewart JH, Bertoni AG, Staten JL, et al. Participation in surgical oncology clinical trials: gender-, race/ethnicity-, and age-based disparities. Ann Surg Oncol 2007;14:3328-34.

31 Gerrand $\mathrm{CH}$, Billingham LJ, Woll PJ, et al. Follow up after primary treatment of soft tissue sarcoma: a survey of current practice in the United Kingdom. Sarcoma 2007;2007:1-6.

32 Greenberg DD, Crawford B. Surveillance strategies for sarcoma: results of a survey of members of the musculoskeletal tumor Society. Sarcoma 2016;2016:1-5.

33 Ries Z, Gibbs CP, Scarborough MT, et al. Pulmonary surveillance strategies following sarcoma excision vary among orthopedic oncologists: a survey of the musculoskeletal tumor Society. lowa Orthop J 2016;36:109.
34 Cipriano CA, Jang E, Tyler W. Sarcoma surveillance: a review of current evidence and guidelines. J Am Acad Orthop Surg 2020;28:145-56.

35 Barofky I, Sugarbaker PH. Determinants of patient Nonparticipation in randomized clinical trials for the treatment of sarcomas. Am J Clin Oncol 1979;2:237-46.

36 Creel AH, Losina E, Mandl LA, et al. An assessment of willingness to participate in a randomized trial of arthroscopic knee surgery in patients with osteoarthritis. Contemp Clin Trials 2005;26:169-78.

37 Agoritsas T, Deom M, Perneger TV. Study design attributes influenced patients' willingness to participate in clinical research: a randomized vignette-based study. J Clin Epidemiol 2011;64:107-15.

38 Halpern SD, Karlawish JHT, Casarett D, et al. Hypertensive patients' willingness to participate in placebo-controlled trials: implications for recruitment efficiency. Am Heart J 2003;146:985-92.

39 Domecq JP, Prutsky G, Elraiyah T, et al. Patient engagement in research: a systematic review. BMC Health Serv Res 2014;14:89. 